\title{
Causality and cointegration of stock markets within the Asian growth triangle
}

\author{
$\underline{\text { S.Z. Abidin }}^{\text {a }}$ and A. Banchit ${ }^{\mathrm{b}}$ \\ ${ }^{a}$ Faculty of Agribusiness and Commerce, Lincoln University, P O Box 85084, Lincoln 7647, New Zealand, \\ ${ }^{b}$ Faculty of Business Management, Universiti Teknologi Mara (UiTM), 94300, Kota Samarahan, Sarawak, \\ Malaysia \\ Email:sazali.abidin@lincoln.ac.nz
}

\begin{abstract}
This paper explores the co-integration and causality relationships amongst the Asian Triangle stock exchange indices. These Asian triangle regions consists of the eight key markets of Shanghai, Shenzhen, Hong Kong, Thailand, Philippines, Malaysia, Korea, and Indonesia. In applying modern unit root and cointegration econometric techniques that will allow for structural breaks over our sample period of data (October 2002 to August 2018), we found that there is no co-integration within these markets except for that between Shenzhen and Shanghai. By using Granger causality tests, Johansen, and impulse response functions, we will show that stock price changes in Hong Kong have more impact on Asian triangle markets than that of any other market. More specifically, price changes in the Philippines market can be used to gauge the succeeding movement of the other Asian markets excluding Shenzhen and Shanghai. We develop various potential and current relationships within these markets that would lead one to further empirical research. Our overall finding was that Hong Kong being the epicenter still plays an important role in assisting and motivating emerging markets as shown through our impulse response testing and would therefore not yet rule out the importance of developed economies.
\end{abstract}

Keywords: China, causality, cointegration, stock returns, Asian market 


\section{INTRODUCTION}

Emerging Markets have seen a drastic increase in foreign investment in recent decades. Masood and Gooptu (1993) found that the flow of portfolio investments into emerging markets has increased from $\$ 6.2$ billion in 1987 to $\$ 37.2$ billion in 1993 to well over a Trillion dollars in 2008. The impact these markets are having on the global economy can no longer be ignored and at the forefront of global growth is the Asian triangle lead by the people's republic of China. Numerous papers exist that address the issue of capital markets within emerging economies (Ma 1993: Shim 1989: Heston et al 1995). Although these papers contribute important research within the field of financial markets and co integration there lacks a compelling study that focuses on a select region and the relationship between various geographically located nations. As the South China growth triangle has opened up in recent years to international trade it has resulted also in substantial growth within the greater Asian region. Wei et al (1995) and $\mathrm{Hu}$ et al (1997) studied the cointegration relationship amongst different financial markets. Building ideas found within existing empirical studies we intend to concentrate on the Asian regions financial markets. Empirical studies have concentrated on China and other major economies (Ma, 1996: Su and Heisher, 1997) but tend to overlook the effect of major economies on neighboring countries. In this paper we intend to focus on the Asian region and the relationship between their respected financial markets. We extensively evaluate historical data from Hong Kong, Malaysia, Indonesia, Thailand, Korea, Philippines, and the two Chinese power exchanges of Shanghai and Shenzhen.

We test a unique data set from eight leading Asian triangle nations' stock exchanges to determine if various relationships exist. Within our methodology we utilize various advanced econometric techniques such as ADF Unit root test, Engle-Granger cointegration, Johansen cointegration, Granger causality, and impulse response function tests. From these tests we discover various compelling statistical evidence to explain the relationships between the Asian triangle stock exchanges. The most compelling finding within our empirical evidence is that of the co integration amongst China's Shanghai and Shenzhen index and the impulse response of Hong Kong being the epicenter for the Asian triangle markets.

\section{LITERATURE REVIEW}

There has been an array of empirical studies on equity markets and segmentation includes contributions by numerous acclaimed academics. Errunza and Losq (1987), Bekaert and Harvey (1995), and Heston et al (1995) all took similar approaches in creating and applying statistical models to derive empirical evidence supporting the time-varying co integration of various equity markets. Adler and Dumas (1992), and Foerster and Karolyi (1993) also venture into the avenue of investigating investment decisions and variation of returns according international markets and their co-integration. As the world becomes increasingly interdependent and globalization takes further hold academic research is increasingly being capable of tracing market interdependence. Dating back to Granger and Morgenstern (1970), Ripley (1973), Hilliard (1979), and as recent as Huang et al (2000) evidence has pointed towards a common result. The observation taken from existing research shows that national stock indices are a reflection of their stock indices but a by-product of this is that only such weak correlations existed. This result confirming that an international stock portfolio could be quite beneficial. Examining deeper the broad findings of academics Hilliard (1979) used an alternative method of spectrum analysis in order to focus on predetermined correlations of ten leading stock markets. His findings supported that of Granger and Morgenstern (1970), and Huang et al (2000). Showing that although contemporaneous correlation existed for intercontinental stock prices, it was found to be weak amongst intracontinental prices. Within this paper we endeavor to evaluate the inter-regional correlation of stock markets within the Asian triangle. In support of that found by Ripley (1973), and Ibbotson et al (1982) our initial hypothesis supports the notion that stock price co movements occur due to geographical locations, partnerships in trade, cultural or economic similarities, and institutional currency relationships. By examining the relationship within the similarities evolving in the Asian triangle circle, we hope to find significant relationships between market movements among the corresponding nations.

Schollhammer and Sand (1987), Dwyer and Harter (1988), and Huang et al (2000) tested using correlation techniques or unit root models the relationship between U.S, Japanese, German, and UK markets. They found that there was a lack of correlation between these stock markets and those variations in price appeared correlated up until the 1987 market crash. This could be found to be a result due to the fact of developed nations such as Germany, USA, UK, and Japan reaching the Zenith of their growth curve and therefore graduating from developing to developed nation status. Our initial findings and empirical study's intend to find that this correlation between markets is significantly stronger in the developing world. These findings and further study are largely reliant on the methodological techniques of those who are conducting the test. Huang et al (2000) 
emphasized this fact that the results of such test on multiple matching market data are highly dependent on how one accurately estimates the correlation matrix co-efficient.

Cheol Eun and Bruce Resnick (1984) attacked this problem from multiple approaches in their paper titled "Estimating the correlation structure of international share prices". Within the paper they compare and contrast various techniques of estimating the direct and indirect methods of determining the correlation coefficients based on the assumption that market movements are correlated with another only due to common factors that are relevant to the global market index. The resultant findings of their study points in favour to using a direct approach method when testing. Another integral finding of this study raised an additional question when estimating the correlation coefficient in the pending stability of long-term and intertemporal periods. Intertemporal stability is supported by Watson (1980) and Philippatos et al (1983) who contend that the shorter the time period considered results in a more stable pattern of co-movement within stock markets. This is especially true before and leading up to the 1987 stock market crash. Recently Longin and Solnik (1995) authenticate evidence of instability within both correlation and covariance coefficients using a multivariate GARCH model. On the other hand Maldonado and Saunders (1981) refute the findings of stability and contend that through their study of the US, Japanese, German, Canadian, and U.K. markets that intertemporal stability is non-existent. Both views aside and taking an unbiased view it is evident that due to the unabated and synchronized growth amongst the various countries, there exists a valid reason to believe interdependence amongst stock markets is on the rise especially those that are leveraged on the same growth factors such as developing nation economies. An alternative method of investigating the interdependence of stock returns across multiple markets is that of focusing on the transmission mechanism. Multilateral interactions exist via the impulse response function using a multi-country VAR model as done by Eun and Shim (1989). Academics have since questioned the validity of Eun and Shim (1989) findings as they focused on the significance level as per the positive absolute value of the impulse response function and neglected to examine if any statistical significance in fact supported their findings. Eun and Shim (1989) also found that innovations from the U.S.A. markets were rapidly transmitted abroad to outer countries but the innovations moving abroad did not significantly coincide an impact back on the returns of US stock. In light of this it is seen that national markets are proven to be generally consistent in supporting the efficient information hypothesis.

Other studies undertaken within the field of market co-intergration have developed some interesting findings as to if this phenomenon exits and if so, in what situation is it most evident. Joen and Von Furstenburg (1990) took and analysis of the interaction between three major international markets and tested these using impulse response functions of a VAR model. Extracting market close daily returns of U.S.A, Britain, Germany, and Japan from January 1986 to November 1988.In doing this they evaluated the correlation coefficient matrix and found that the role of the U.S. market leadership has diminished and undergone some serious structural changes since the 1987 stock crash. In result of this diminished U.S. leadership role Joen and Furstenburg discovered that the Japanese leadership role has increased as a result of the U.S. decrease. This finding is alongside that we plan to achieve within our study of the Asian triangle in determining if China's markets do in fact play a leading role within these eight national markets similar to that of pre-1987 U.S.A. Also as result of the above mentioned study by Joen and Furstenburg it was found that the phenomenon of stock price co movement appears to be consistently on the rise mainly due to increased globalization and advancements in technology. By utilizing unit root and co integration techniques alongside other econometric methods we intend to examine the relationship through a Granger Causality model of the Asian triangle. The granger technique provides a more accurate method of testing market relationships as described by Granger et al (2000). As a result of the array of academic research, we intend to test if there is a co-integrating relationship between the eight Asian triangle markets and if so, which are the leading markets, and what impact do they have on their outlying partners?

\section{DATA, METHODOLGY, AND DISCUSSIONS}

The data sample collected for this study is the daily closing stock price of each respective countries market index. Taking this daily index data beginning October 2002 through August 2018. All data has been obtained through Datastream, exchange websites, and external resources. We have calculated the daily percentage change of stock prices using the conventional method of logarithmic change in price.

\subsection{ADF unit root test}

The first method of testing we propose is that of testing whether our data series has one or more unit roots in order to determine the validity of testing for co-intergration. The intuition behind the Augmented Dickey-Fuller $(\mathrm{ADF})$ is to test if the data series is integrated and if so then the lag level of the series $\left(\mathrm{y}_{t-1}\right)$ will result in no relevant information in order to predict change in $y_{t}$ other than the one found in the lagged changes $\left(\Delta y_{t}-k\right)$. The ADF unit root test has widely been used to determine the stationarity of a certain time series. Although 
popular in its practical use, the ADF test can lead to erroneous conclusions if an event such as an oil shock or depression occurs as found by Perron (1989). The point of the matter is that the ADF test fails to reject the Null hypothesis if structural breaks are present within the data. Academics in the past such as Perron and Vogelsang (1992) have used dummy variables to eliminate the effect of structural breaks within data. Although this is a valid attempt to mitigate the problem we believe that the use of dummy variables has its own problems as found in Zivot and Andrews (1992) paper and we have decided to not implement the use of dummy variables.

Table 1 - Tests for orders of integration

\begin{tabular}{|c|c|c|c|c|c|}
\hline \multirow[t]{4}{*}{ Hypothesis } & \multirow{2}{*}{\multicolumn{2}{|c|}{$\begin{array}{l}\mathrm{H}_{0}: \mathrm{I}(1) \\
\mathrm{H}_{1}: \mathrm{I}(0)\end{array}$}} & \multirow{2}{*}{\multicolumn{2}{|c|}{$\begin{array}{l}\mathrm{H}_{0}: \mathrm{I}(2) \\
\mathrm{H}_{1}: \mathrm{I}(1)\end{array}$}} & \multirow{4}{*}{$\begin{array}{r}\text { Results from } \\
\text { ADF test } \\
\text { (no trend) }\end{array}$} \\
\hline & & & & & \\
\hline & $\mathrm{ADF}($ no trend) & $\mathrm{ADF}$ (with trend) & $\mathrm{ADF}$ (no trend) & $\mathrm{ADF}$ (with trend) & \\
\hline & t-statistics & t-statistics & t-statistics & t-statistics & \\
\hline $\mathrm{HK}$ & -2.100 & -2.905 & $-17.239 * * *$ & $-17.238 * * *$ & I(1) \\
\hline Malaysia & -2.283 & -2.348 & $-11.294 * * *$ & $-11.292 * * *$ & I(1) \\
\hline Indonesia & -0.911 & -2.160 & $-10.393 * * *$ & $-10.401 * * *$ & I(1) \\
\hline Thailand & -1.615 & -1.530 & $-15.702 * * *$ & $-15.710 * * *$ & I(1) \\
\hline Korea & -1.442 & -1.832 & $-31.371 * * *$ & $-31.368 * * *$ & I(1) \\
\hline Philippines & -1.688 & -1.689 & $-56.287 * * *$ & $-56.281 * * *$ & I(1) \\
\hline Shanghai & -2.144 & -2.743 & $-14.357 * * *$ & $-14.360 * * *$ & I(1) \\
\hline Shenzhen & -1.035 & -2.054 & $-26.208 * * *$ & $-26.213 * * *$ & I(1) \\
\hline
\end{tabular}

$*, * *, * * *$ indicate rejection of the null of non-stationarity at the $10 \%, 5 \%$ and $1 \%$ significance level, respectively

Critical value for ADF test (no trend): -3.48 at $1 \%$ significance level, -2.88 at $5 \%$ level, -2.58 at $10 \%$ level

Critical value for ADF test (with trend): -4.03 at $1 \%$ significance level, -3.44 at $5 \%$ level, -3.15 at $10 \%$ level

\subsection{Engle-Granger co integration test}

The Engle-Granger bivariate co integration test (Engle and Granger, 1987) is a conventional method used to test the convergence of national share markets within the Asian triangle. Similar to that done by MacDonald and Taylor (1993) who investigated the relationship between regional house prices we have selected eight Asian stock exchanges in order test their relationship. We aim to detect pair wise co integration amongst the stock exchanges returns within our data sample. We implement an Engle-Granger bivariate test on our empirical data series. The first step requires a regression of one stock exchange data series $\left(Y_{t}\right)$ against another stock exchange data series $\left(X_{t}\right)$ :

$$
Y_{t}=\alpha+\beta X_{t}+\varepsilon_{t}
$$

Our results as displayed in Table 2 analyses the eight Asian triangle stock indices time series, which in total results in 28 pairs of stock indices. We have used the SIC as mentioned above in order to choose the optimal lag lengths in the ADF test for the purpose of consistency within our paper. We have discovered that at the $5 \%$ significance level, six residuals are significantly rejected from the overall sample of 56 possible hypotheses.

Table 2 - Bivariate cointegration test

\begin{tabular}{lcccccccc}
\hline & HK & Malaysia & Indonesia & Thailand & Korea & Philippines & Shanghai & Shenzhen \\
HK & - & -2.292 & $-3.436 * * *$ & -2.253 & -2.447 & -1.880 & $-3.559 * * *$ & $-3.398 * *$ \\
Malaysia & -2.003 & - & -2.280 & -2.572 & $-3.024 * *$ & -2.469 & -2.225 \\
Indonesia & -1.938 & -0.993 & - & -0.815 & -2.577 & -0.387 & -1.581 & -1.370 \\
Thailand & -1.690 & -2.255 & -1.584 & - & -1.466 & -1.918 & -1.862 & -1.976 \\
Korea & -1.801 & -2.633 & -2.710 & -1.626 & -1.75 & -1.889 & -1.650 \\
Philippines & -1.577 & -2.248 & -1.710 & -2.086 & -1.923 & -1.755 & -1.689 & -1.676 \\
Shanghai & -2.796 & -2.082 & -2.577 & -2.335 & -2.378 & -2.157 & -1.031 & $-4.512 * * *$ \\
Shenzhen & -2.450 & -1.045 & -1.674 & -1.560 & -1.284 & $-1.023 * * *$ & - \\
\hline
\end{tabular}

$*, * *, * * *$ indicate rejection of the null of non-stationarity at the $10 \%, 5 \%$ and $1 \%$ significance level, respectively

Critical value for $\mathrm{ADF}$ test (no trend): -3.43 at $1 \%$ significance level, -2.86 at $5 \%$ level, -2.57 at $10 \%$ level 
It is evident from the results above that there is only one pair wise co integrating relationship identified within our unique data series and 28 pairs. This relationship is between Shanghai and Shenzhen. This could potentially be down to the fact that they are both Chinese markets and therefore are driven by similar macro economic variables. It is also important that we recognise the one way relationship between Hong Kong and ShanghaiShenzhen. This co integrating relationship between Hong Kong and Chinas stock exchange is an important relationship as in links the developed world with the developing world. Hong Kong has historically catered for investors who wanted a slice of Asia's growth pre-China's relaxation of foreign investment laws. In summary, our results indicate that more than half the stock exchanges within our data sample are not interlinked. This indicates that the evidence of convergence in the long-run within these eight stock exchange index time series is relatively weak. The only significant finding thus far from our methodological testing is that of China's share markets and also a leading relationship from Hong Kong.

\subsection{Johansen co integration test}

The Johansen co integration test (Johansen, 1988) is a multivariate VAR model based on the assumption that different sets of data or variables tend to converge at a certain point in time. This method has been conventionally used to test the existence of national stock exchange returns convergence (Huang, 2000). Academics have also used Johansen co integration as a method to estimate house price movements over a certain time period (Macdonald and Taylor, 1993). It is a useful econometric approach dependant on the underlying data series and therefore we have found it beneficial in application within our area of study. We plan to detect the co integration relationship between the Asian triangle national stock exchange returns.

The VAR is determined as

$$
\Delta \vec{Y}_{t}=\delta+\Gamma_{1} \Delta \vec{Y}_{t-1}+\ldots+\Gamma_{p-1} \Delta \vec{Y}_{t-p+1}+\Pi \vec{Y}_{t-1}+\varepsilon_{t}
$$

Through applying the Johansen co integration test it enables us to implicate a trace test and also a maximum eigenvale test to examine the hypothesis about the rank in (3). In the case of our hypothesis testing we should stop rejecting the null when the test statistic just goes below the respective critical value. According to the method behind the Johansen test we have allocated and selected the optimal lag length based on five criteria. These criteria are 1) Sequential modified LR test statistics (LR), 2) Final Prediction error (FPE), 3) Akaike information criterion (AIC), 4) Schwarz Criterion (SC), 5) Hannan-Quinn information criterion (HQ). Using each of the five mentioned criteria we take the smallest value points in order to indicate the optimal lag length as done by Verbeek (2008). In order to conduct the Johansen test it was vital that we chose the optimal lag length before we embarked on testing our hypothesis. We have selected 1 as the appropriate lag length based on SIC. The critical values within our Johansen test will be dependent on the number of common trends and the non-stationary components, along with the inclusion of a constant trend.

\subsection{Granger causality test}

Granger Causality test as developed by Engle and Granger (1987) offers an accurate methodological method of gauging the path of price diffusion (Picken, 2007) or in our case market price movements or returns. Our Granger causality test has been used to test the variation in the dependant variable caused by the past independent variables. At the 5\% significance level with one degree of freedom we could statistically identify 17 casual flows, four of these happen to form 2 interesting Two-way casual flows. These two bi-directional causality flows among the Eight Asian triangle stock indices are Korea- Thailand, and Thailand- Philippines. The relationship between the eight exchanges within our data set is presented below.

Table 3 - Granger causality test

\begin{tabular}{|c|c|c|c|c|c|c|c|c|}
\hline & HK & Malaysia & Indonesia & Thailand & Korea & Philippines & Shanghai & Shenzhen \\
\hline HK & - & 1.202 & 1.304 & $6.782 * * *$ & $13.534 * * *$ & 0.154 & 0.400 & 3.695 \\
\hline Malaysia & $7.238 * * *$ & - & $23.999 * * *$ & 2.243 & 0.031 & 3.200 & 0.747 & 0.142 \\
\hline Indonesia & 0.018 & 0.042 & - & 28.090 & $10.112 * * *$ & 2.267 & 0.569 & 0.000 \\
\hline Thailand & 0.010 & 1.371 & $7.481 * * *$ & - & $14.682 * * *$ & $7.968 * * *$ & 0.332 & 1.579 \\
\hline Korea & 0.376 & 0.029 & 0.478 & $13.221 * * *$ & - & 0.278 & 0.680 & 0.034 \\
\hline Philippines & $15.326^{* * *}$ & $11.302 * * *$ & $24.926 * * *$ & $37.713 * * *$ & $4.350 * *$ & - & 0.058 & 0.034 \\
\hline Shanghai & 0.170 & 0.353 & $4.360 * *$ & 1.131 & 0.001 & 0.533 & - & $7.110 * * *$ \\
\hline Shenzhen & 0.119 & 0.819 & $3.897 * *$ & 2.346 & 0.001 & 0.734 & 0.893 & - \\
\hline
\end{tabular}

$* *, * * *$ indicate rejection of the null of non-stationarity at the $5 \%$ and $1 \%$ significance level, respectively 
From our causality testing, we also found unidirectional causality relations exists. Hong Kong Granger tests revealed that its index causes the stock exchange of Thailand and Korea to move. The index of Malaysia causes movements in the index of Hong Kong and Indonesia, Indonesia granger causes Korea, Shanghai granger caused Indonesia and Shenzhen, and Shenzhen Granger causes Indonesia. From this evidence one could conclude that Indonesia was the most vulnerable exchange as a result of movements in other leading markets before it. Surprisingly, although Shanghai and Shenzhen markets both exist within the same country it was found within our methodological testing that no bi-directional relationship existed between them. This finding confirms that Shanghai Granger causes movements in Shenzhen but Shenzhen Granger does not cause movements in Shanghai. Our findings imply that Shanghai stock index has a greater status amongst Chinese stock exchanges. The Philippines Granger has a significant impact on five important Asian exchanges. These are Hong Kong, Malaysia, Indonesia, Thailand, and Korea. The relationship with Thailand is bidirectional and thus plays an important part in our results that show the potential cointegration between two existing Asian markets. This result in the Philippines leaving itself and the two Chinese markets as the only three exchanges it does not impact. This finding at first opens new ideas for further research in looking deeper into the factors that contribute to this impact and why the Philippines has such an important impact on Asian markets. In order to truly understand impulse and the impact on corresponding markets we can not just take the Granger results of markets that play only a single directional impact. Instead we have elected to conclude our testing by running an impulse response function in order to locate the epi-centre of the Asian market indices and if a potential ripple effect exists.

\section{CONCLUSIONS}

Although rapid growth and similar macro economic characteristics exist within the Asian triangle nations. It is of surprise that the eight markets tested within our empirical findings do not support strong integration. EngleGranger testing found six statistically significant co-integrating relationships but with only one pair wise co integration. It was found that more than half of exchanges are not interlinked. Further testing using the Johansen method resulted in seven common stochastic trends that drove the eight Asian markets. The important findings resultant of Johansen testing was that no long-run convergence existed within our data series. Granger Causality found two bidirectional causality flows. These flows were between Korea-Thailand, and ThailandPhilippines. Although Shanghai and Shenzhen markets both exist within the same country our methodological testing found that no bi-directional relationship existed. This is surprising due to the similar nature of Shanghai and Shenzhen in culture (Confucianism) and language (Chinese) would lead one to suspect that integrated capital markets would exist. This is not the case within our findings, although Shanghai and Shenzhen have found to be statistically co-integrated according to Engle-Granger methodology. It has been suggested in previous papers (Hunag et al, 2000) and is becoming slowly apparent as time passes by, that an ease of restrictions on capital movements amongst global markets especially those of the Asian triangle would serve catalyst in giving greater market integration. Our findings also pointed towards the fact that Shanghai stock exchange has a greater status amongst Chinese markets. Through our final testing method of impulse response we were capable of testing the main epicentre of the Asian stock exchanges. Hong Kong has been found to be the key engine behind Indonesia, Korea, Malaysia, and Thailand. We have had numerous minor findings within our methods of testing but the key factor found within our empirical research is that Hong Kong is still the leading nation as found from impulse response testing and therefore proves although emerging markets are continuing to have large impact on financial markets it is the developed nations such as Hong Kong who still lead the way and have a greater overall impact.

\section{REFERENCES}

Adler, M., \& Dumas, B. (1983). International portfolio selection and corporation finance: a synthesis. Journal of Finance, 38, $925 \pm 984$.

Bekaert, G., \& Harvey, C. R. (1995). Time-varying world market integration. Journal of Finance, 50, $403 \pm 444$

Dwyer, G. P. Jr., \& Harter, R. W. (1988). Are national stock markets linked? Federal Reserve Bank of St. Louis Review, 39, $3 \pm 14$.

Engle, R. F., \& Granger, C. W. J. (1987). Cointegration and error correction: representation, estimation, and testing. Econometrica, 55, 251 \pm 276 .

Errunza, V., \& Losq, E. (1987). How risky are emerging markets? Journal of Portfolio Management, 14(1), $62 \pm 77$

Eun, C. S, \& Shim, S. (1989). International transmission of stock market movements. Journal of Financial Quantitative Analysis, 24, 241士256. 
Eun, C and Resnick, B. (1984) Estimating the Correlation Structure of International Share Prices, The Journal of Finance, 39(5), pp. 1311-1324.

Foerster, S. R., \& Karolyi, G. A. (1993). International listings of stocks: the case of Canada and the U.S. Journal of International Business Studies, 24, $763 \pm 784$.

Granger, C. W. J., Huang, B.-N., \& Yang, C.-W. (2000). A bivariate causality between stock prices and exchange rates: evidence from recent Asian flu. Quarterly Review of Economics and Finance, in press.

Heston, S. L., Rouwenhorst, K. G., \& Wessels, R. E. (1995). The structure of international stock returns and the integration of capital markets. Journal of Empirical Finance, 2, $173 \pm 197$.

Hilliard, J. (1979). The relationship between equity indices on world exchanges. Journal of Finance, 4, $103 \pm 114$.

Hu, J. W.-S., Chen, M.-Y., Fok, R. C. W., \& Huang, B.-N. (1997). Causality in volatility spillover effects between US, Japan and four equity markets in the South China growth triangle. International Financial Market, Institution and Money, 7, 351 367.

Huang, B. Yang, C. Hu, J. (2000) Causality and cointegration of stock markets among the United States, Japan and the South China Growth Triangle, International review of financial analysis, 9(3), pp.281-297.

Ibbotson, R., Carr, R., \& Robinson, A. (1982). International equity and stock returns. Financial Analysts

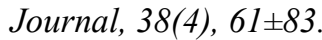

Johansen, S. (1988), Statistical Analysis of Cointegration Vectors, Journal of Economic Dynamics and Control, 12, 231-254.

Joen, B. N., \& Von Furstenberg, G. M. (1990). Growing international co-movement in stock price indexes. Quarterly Review of Economics and Finance, 30, 15 \pm 30 .

Longin, F., \& Solnik, B. (1995). Is the correlation in international equity returns constant: 1960 1990 ? Journal of International Money and Finance, 14(1), $3 \pm 26$.

Ma, C. K. (1993). Financial market integration and cointegration tests. In S. R. Stansell (Ed.), International financial market integration (pp. 228土298). Cambridge, MA: Blackwell.

Ma, X. (1996). Capital controls, market segmentation and stock prices: evidences from the Chinese stock markets. Pacific-Basin Financial Journal, 4, $219 \pm 239$.

MacDonald, R. and Taylor, M. P. (1993) Regional house prices in Britain: Long-run relationships and shortrun dynamics, Scottish Journal of Political Economy, 40(1), pp. 43-55.

Mackinnon, J. Huag, B. Michelis, M. (1999) Numerical distribution functions of likelihood ratio tests for cointegration, Journal of applied econometrics, 14(5).

Maldonado, R., \& Saunders, A. (1981). International portfolio diversification and the intertemporal stability of

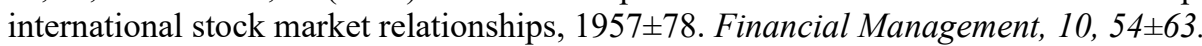

Masood, A., \& Gooptu, S. (1993). Portfolio investment flows to developing coumtries. Finance and Development, 30(1), $9 \pm 12$.

Perron, P., \& Vogelsang, T. J. (1992). Nonstationarity and the level shifts with an application to purchasing power parity. Journal of Business and Economic Statistics, 10(3), 301 \pm 320 .

Philippatos, G. C., Christofi, A., \& Christofi, P. (1983). The intertemporal stability of international stock

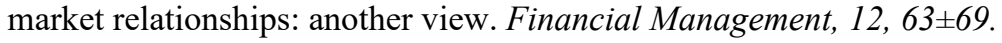

Picken, D. Luo, Z. and Liu, D. (2007) Granger causality among house price and macroeconomic variables in Victoria, Pacific Rim Property Research Journal, 6(8), pp. 56-74.

Ripley, D. M. (1973). Systematic elements in the linkage of national stock market indices. Review of Economics and Statistics, 55, 356 361 .

Schollhammer, H., \& Sand, O. C. (1987). Lead \pm lag relationships among national equity markets: an empiricalinvestigation.

Shim, S. (1989), International transmission of stock market movements, Journal of financial and quantitative analysis, 24(2).

Sims, C. (1980) Macroeconomics and reality, Econometrica,48, 1-48.

S. J. Khoury \& A. Ghosh (Eds.), Recent Development in International Banking and Finance (Vol. 1, pp. 149 \pm 168).

Watson, J. (1980). The stationarity of inter-country correlation coefficients: a note. Journal of Business Finance \& Accounting, 7, $297 \pm 303$.

Wei, K. C. J., Liu, Y.-J., Yang, C.-C., \& Chaung, G.-S. (1995). Volatility and price change spillover effects across the developed and emerging markets. Pacific-Basin Financial Journal, 3, 113 \pm 136.

Zivot, E., \& Andrews, D. W. K. (1992). Further evidence on the great crash, the oil-price shock, and the unitroot hypothesis. Journal of Business and Economic Statistics, 10(3), $251 \pm 270$. 